Indexed by

\title{
THE INFLUENCE OF STEEL FIBRES AND RPC THICKNESS ON THE BEHAVIOUR OF HYBRID COLUMNS UNDER CONCENTRIC LOADING
}

Crossref

\author{
Layla A. Yassin \\ Department of Civil \\ Engineering, University of \\ Technology, Baghdad, Iraq
}

\author{
Alyaa H. Mohammed \\ Department of Civil \\ Engineering, University of \\ Technology, Baghdad, Iraq
}

\author{
Farah L. Rauf \\ Department of Civil \\ Engineering, University of \\ Technology, Baghdad, Iraq
}

KOBSON

Key words: hybrid concrete, normal concrete, reactive powder concrete, short columns, steel fibres, concentric loading, rectangular section

doi:10.5937/jaes0-34451

Cite article:

A. Yassin L., H. Mohammed A., L. Rauf F. (2022) THE INFLUENCE OF STEEL FIBRES AND RPC THICKNESS ON THE BEHAVIOUR OF HYBRID COLUMNS UNDER CONCENTRIC LOADING, Journal of Applied Engineering Science, 20(2), 440 - 446, DOI:10.5937/ jaes0-34451

Online aceess of full paper is available at: www.engineeringscience.rs/browse-issues 


\title{
THE INFLUENCE OF STEEL FIBRES AND RPC THICKNESS ON THE BEHAVIOUR OF HYBRID COLUMNS UNDER CONCENTRIC LOADING
}

\author{
Layla A. Yassin*, Alyaa H. Mohammed, and Farah L. Rauf \\ Department of Civil Engineering, University of Technology, Baghdad, Iraq
}

In this paper a test was performed on six reinforced concrete rectangular columns subjected to concentric loading up to failure. The material used in this investigation included normal concrete, NC, and reactive powder concrete, RPC. Two columns were cast as control specimens with NC and RPC. The remaining four were of hybrid combination having the NC in the centre and the RPC surrounded it. Variables investigated were the effect of steel fibre volumetric ratio, $V_{f}(0.5,1$ and 1.5) as well as the thickness of the external $R P C$ part, (40 and 20) $\mathrm{mm}$. The columns were of rectangular section having the dimensions of $(100 \times 200 \times 740) \mathrm{mm}$. Data recorded included: crack and ultimate loads as well as the longitudinal and lateral strains. Experimental results indicated that the behaviour of the hybrid reinforced concrete columns were approaching that of the full RPC.

Key words: hybrid concrete, normal concrete, reactive powder concrete, short columns, steel fibres, concentric loading, rectangular section

\section{INTRODUCTION}

For more than 20 decades, concrete was and still considered as the principal construction material. The development of this material is progressing, from normal concrete, NC, through high strength concrete, HSC, reaching to ultra-high-performance concrete (UHPC) referred to as reactive powder concrete (RPC). The latter two are produced by adding steel fibres with other additives to the normal concrete. Cracks in HSC or UHPC loaded members are bridged by the fibres used, improving the ultimate tensile strength, toughness and energy absorption capability as compared with members cast with concrete without fibres, as shown in Figs.1, 2 and 3.

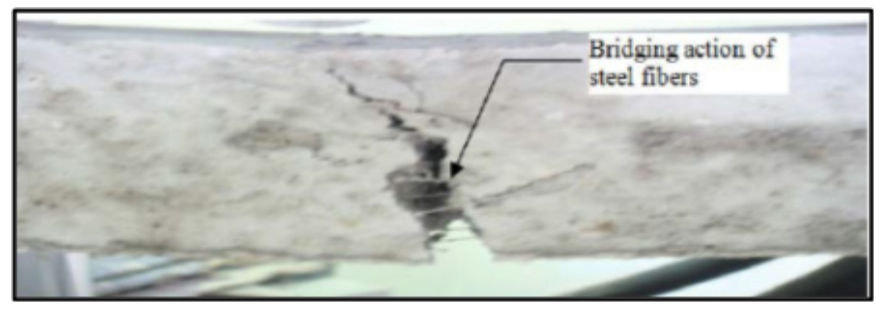

Figure 1: Bridging Action of Steel Fibres on Concrete [3]

This improvement was registered over the last 5 decades. Although the properties of HSC or UHPC are so good, their use was rather limited because of the extremely high prices (about 20 times the cost of NC). [4, 5 and 6] UHPC (or RPC) mechanical and durability properties allowed for longer service lives and decreased maintenance costs. [4 and 7] HSC and RPC are more uniform and homogeneous than NC but more brittle. Fractures in $\mathrm{NC}$ are normally appeared with the emergence of micro-

*layla.a.yassin@uotechnology.edu.iq cracks followed by the widening of macrocracks resulting in a quasi-brittle behaviour. The use of normal reinforcement will help in limiting the widening of macrocracks. To decrease the production cost of these kinds of concrete, some scientist introduced the hybrid concrete, $\mathrm{HC}$, by constructing structural elements cast monolithically from NC with other types of concrete such as HSC, RPC and self-compacting concrete, SCC. This production helped in improving the quality of $\mathrm{NC}$ construction into becoming more robust. [8, 9, 10, 11 and 12] $\mathrm{HC}$ structural elements should only be used in portions of the construction that are likely to be exposed to harsh environments, mainly to increase the strength of the structure without increasing its weight; such structural elements will be stronger and more economical than those cast with plain NC. This paper includes an experimental investigation on six reinforced concrete rectangular columns subjected to concentric loading until failure.

\section{AIM OF WORK}

This paper investigated the effect of steel fibre volumetric ratios and the thickness of the external RPC part on the failure load and toughness in short HC columns of rectangular sections. The first variable studied was the steel fibre volumetric ratio, $V_{f},(0.5,1$ and 1.5$)$, these ratios were selected based on research in literature [13] that suggested the volumetric ratio to be less than 2 to produce better strength and workability. The other variable was the thickness of the RPC layer, (40 and 20) mm.

\section{EXPERIMENTAL WORK}

Six short rectangular columns, with a cross-sectional area of $(100 \times 200) \mathrm{mm}$ and a height of $740 \mathrm{~mm}$, reinforced with $4 \phi 10$ longitudinal bars confined with $\phi 6$ ties 
spaced at $100 \mathrm{~mm}$, were cast for this investigation. Materials used included NC and RPC. Two specimens were cast with NC and RPC as control columns. The remaining four were cast with $\mathrm{HC}$ locating the $\mathrm{NC}$ at the centre surrounded by the RPC. A flowchart of the experimental work is illustrated below:

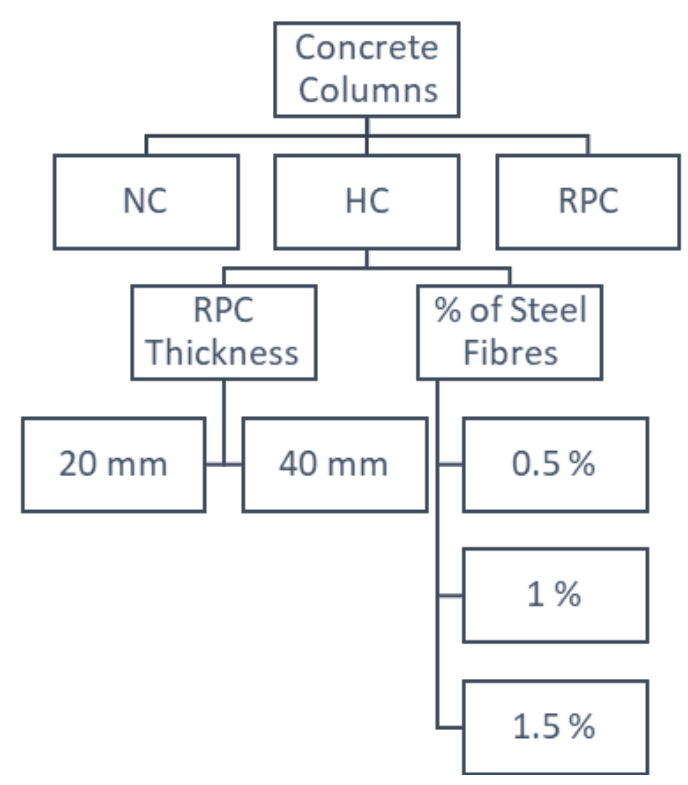

The $40 \mathrm{~mm}$ thickness-RPC layer of three HC columns, contained $0.5,1$ and $1.5 \%$ micro steel fibres, while the $20 \mathrm{~mm}$ thickness-RPC layer of the last HC columns contained $1 \%$ micro steel fibres. Specimens were designated based on material used, steel fibre ratios and the thickness of RPC layer (variable studied). For example, the specimen ( $\mathrm{HC}-1-20)$ refers to a hybrid concrete column with $1 \%$ steel fibre ratio and $20 \mathrm{~mm}$ thickness of RPC; details of specimens are shown in Table 1.

Table 1: Details of Research Specimens Studied

\begin{tabular}{|c|c|c|c|c|}
\hline No. & Specimens & $\% V_{f}$ & $\begin{array}{l}\text { Thickness } \\
{[\mathrm{mm}]}\end{array}$ & Variables \\
\hline 1 & $\mathrm{NC}$ & 0 & $\begin{array}{c}\text { Full NC, } \\
100\end{array}$ & \multirow{3}{*}{$\begin{array}{c}\text { Control } \\
\text { Specimens }\end{array}$} \\
\hline 2 & RPC-1 & 1 & $\begin{array}{c}\text { Full RPC, } \\
100 \\
\end{array}$ & \\
\hline 3 & HC-1-40 & 1 & $\mathrm{RPC}, 40$ & \\
\hline 4 & $\mathrm{HC}-0.5-40$ & 0.5 & $\mathrm{RPC}, 40$ & \multirow{2}{*}{$\begin{array}{l}\text { Steel fibre } \\
\text { ratio\% }\end{array}$} \\
\hline 5 & $\mathrm{HC}-1.5-40$ & 1.5 & $\mathrm{RPC}, 40$ & \\
\hline 6 & HC-1-20 & 1 & RPC, 20 & $\begin{array}{c}\text { RPC } \\
\text { thickness } \\
\mathrm{mm}\end{array}$ \\
\hline
\end{tabular}

\section{Properties of Materials Used}

(1: 1.2: 1.75) (Cement: Sand: Gravel) were the proportions for the NC mix having a cement content of $400 \mathrm{~kg} /$ $\mathrm{m}^{3}$ and compressive and tensile strengths of $28 \mathrm{MPa}$ and $4 \mathrm{MPa}$ respectively; whereas (1: 1: 0.25: (0.005,0.01 and 0.015) (Cement: Fine Sand: Silica Fume: Steel Fibre) were the proportions for the RPC mix having a cement content of $900 \mathrm{~kg} / \mathrm{m}^{3}$ and compressive and tensile strengths of $84 \mathrm{MPa}$ and $16 \mathrm{MPa}$ respectively. The water/ cement ratios for both mixes were 0.5 and 0.22 respectively. For the latter mix, RPC, a $6 \%$ super plasticizer was used with straight steel fibres $(0.2 \mathrm{~mm}$ in diameter and $15 \mathrm{~mm}$ length with 75 aspect ratio and $2600 \mathrm{MPa}$ tensile strength) were used in the RPC mix.

\section{Casting Procedure}

Horizontal steel moulds were used for casting all specimens. The two types of concrete used were mixed earlier then the casting of $\mathrm{HC}$ columns was performed in three steps:

1. The 1 st step started with applying the RPC (20 or 40) $\mathrm{mm}$ layer into the form.

2. The 2nd step started after inserting two steel plates into the form (the location of the plates depends on the thickness of the RPC layer); these plates will separate the two types of concrete used to cast the $\mathrm{HC}$ combination. The NC will be poured in the centre while the RPC will be poured on the sides of the plates.

3. The last step will include completing the casting by applying the RPC mix to the end of the mould. After finishing casting, the two plates must be removed slowly.

To get the properties of the concrete used in this research, destructive tests were performed on control specimens (previously cast following the ASTM standards [14, 15, 16 and 17]. One of the moulds with the reinforcement cage and the concrete is illustrated in Fig. 2.

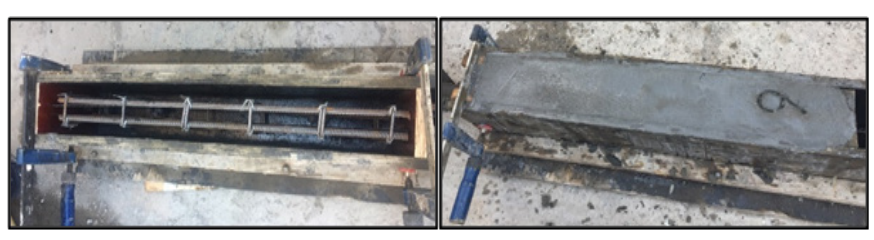

Figure 2: The Photos of the Moulds with the concrete cast within

\section{Specimens' Curing}

Demolding of all specimens were done after two days then curing started for 28 days. The specimens were left for a week to be dried at ambient temperature before testing. 


\section{Test Setup}

Research specimens were tested at the University of Technology / Civil Engineering Department labs using the Avery testing frame system shown in Fig. 3. Which shows the test set-up as well for each specimen in this study.

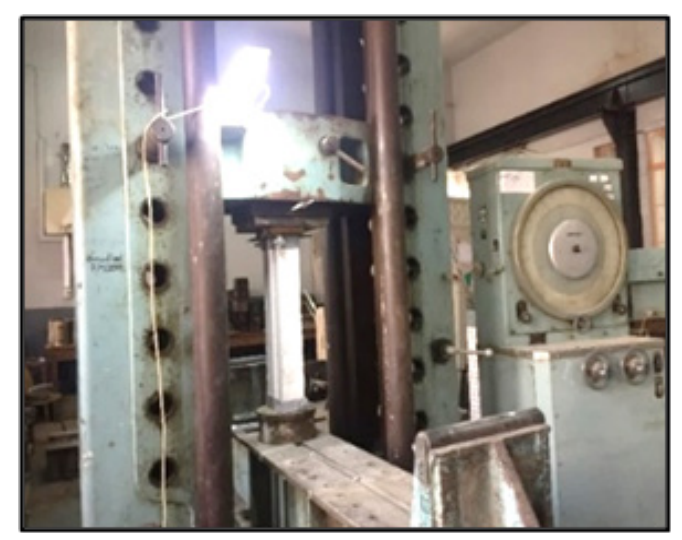

Figure 3: The Avery Testing Frame System

The load was applied concentrically on a steel bearing plate at the top of each column. Two steel rings were supporting the top and bottom of each column to prevent the crush of concrete throughout the test. To register the vertical and horizontal displacements of each column, two LVDTs were attached to the columns at the centre (Fig. 4).
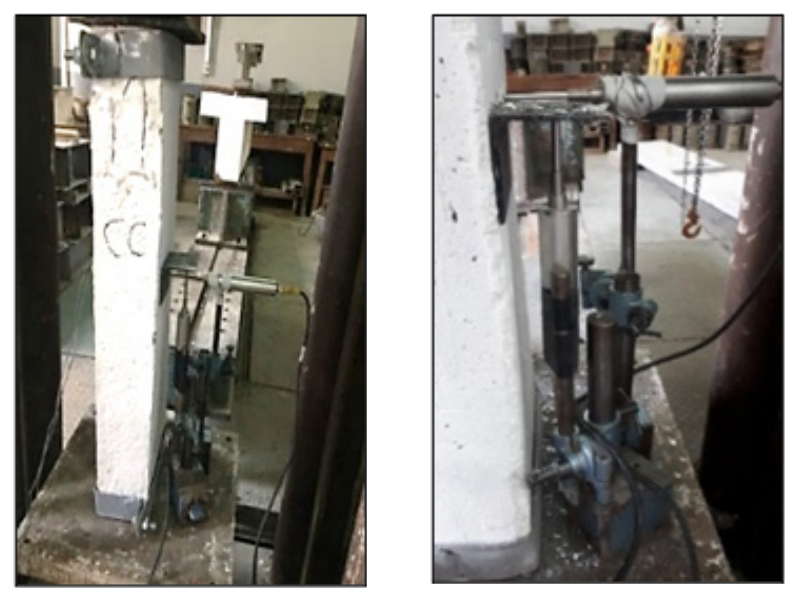

Figure 4: LVDT used in Testing

\section{RESULTS}

Test results are listed in table 2. Cracking loads and displacements were not $100 \%$ accurate but were thought to be close to it based on eye vision and accompanying voices during the test procedure.

Table 2: Summary of All Specimens' Test Results

\begin{tabular}{|c|c|c|c|c|c|c|}
\hline$\dot{z}$ & Name & $\begin{array}{c}\mathrm{P}_{\mathrm{cr}} \\
{[\mathrm{kN}]}\end{array}$ & $\begin{array}{c}\Delta_{\mathrm{cr}} \\
{[\mathrm{mm}]}\end{array}$ & $\begin{array}{c}\mathrm{P}_{\mathrm{u}} \\
{[\mathrm{kN}]}\end{array}$ & $\begin{array}{c}\Delta \mathrm{u} \\
{[\mathrm{mm}]}\end{array}$ & $\begin{array}{c}\% \text { Inc. } \\
\text { in load- } \\
\text { wrp* NC }\end{array}$ \\
\hline 1 & $\mathrm{NC}$ & 220 & 0.121 & 340 & 0.155 & 0 \\
\hline 2 & RPC-1 & 600 & 0.065 & 1030 & 0.12 & 203 \\
\hline 3 & HC-1-40 & 540 & 0.089 & 950 & 0.185 & 179 \\
\hline 4 & HC-0.5-40 & 660 & 0.145 & 720 & 0.170 & 112 \\
\hline 5 & HC-1.5-40 & 700 & 0.045 & 1050 & 0.062 & 209 \\
\hline 6 & HC-1-20 & 400 & 0.130 & 550 & 0.163 & 62 \\
\hline \multicolumn{7}{|l}{ *wrp = with respect to } \\
\hline
\end{tabular}

Fig. 5. shows the photos of all specimens tested throughout this research work. Specimens in Figure (5-a) represent the control specimens NC, RPC-1, and HC-1-40; Fig. (5-b) shows the hybrid columns $\mathrm{HC}-0.5-40$ and $\mathrm{HC}$ 1.5-40, finally Fig. (5-C) shows the hybrid column HC-120.

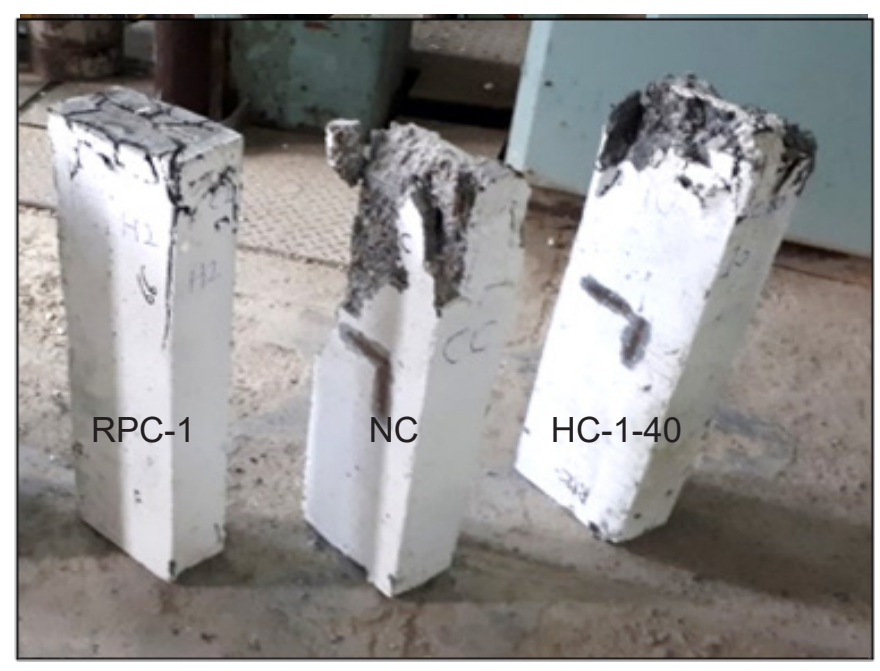

a)

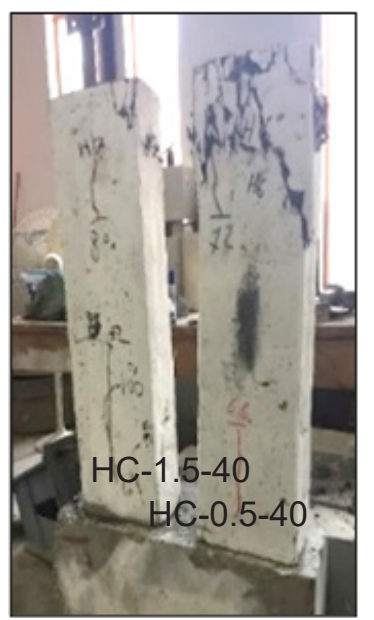

b)

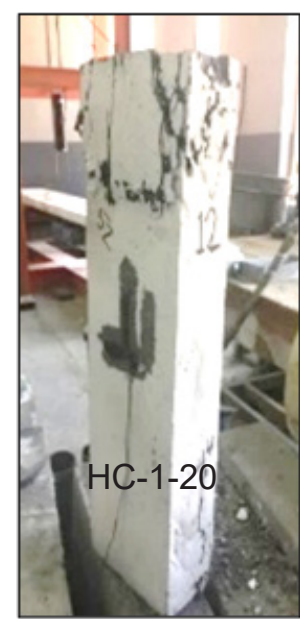

c)

Figure 5: Photos of Tested Specimens 
From economy point of view, the results obtained were considered effective. The tested HC specimens bore higher loads and eventually lower cost than the pure RPC specimens.

\section{Discussing the Mode of Failure}

As shown in Figure 5, the mode of failure for the tested specimens were due to minor cracks starting from the upper and lower corners of the columns and propagating vertically toward the centre of the column. The failure of the NC column was differ nt than the other columns which suffered from more cracks that led eventually to crushing; this crushing led to a conclusion that using the $\mathrm{RPC}$ or the $\mathrm{HC}$ combination in casting columns would be safer than the NC alone.

\section{Discussing Failure Load (Pu)}

The failure loads for the specimens tested in this research are listed in Table 2. These results showed an enhancement of $203 \%$ in the RPC column's failure load with respect to the NC column. The hybrid combination used (with $40 \mathrm{~mm}$ thickness of RPC) gave similar enhancement in the ultimate load with respect to the NC column. This enhancement was $112 \%, 179 \%$ and $209 \%$ for each steel fibers volumetric ratios used $(0.5,1$ and $1.5) \%$ respectively. The hybrid $20 \mathrm{~mm}$ RPC thick layer combination enhanced the failure load about $62 \%$ with respect to the NC column, but this enhancement was about half the value of the hybrid columns with $40 \mathrm{~mm}$ thickness of RPC.

\section{Discussing the Load-Displacement Curves}

Load-displacement curves for the vertical and horizontal displacements are shown in Figures 6 to 9, for the two variables studied in this research.

\section{The first variable/volumetric ratio of steel fibers}

Load-displacement curves of a different steel fibres volumetric ratios columns are shown in Figs. 6 and 7. Fig. 6 , representing the vertical displacements, shows that the load-displacement curve for the NC column is less stiff than any other type of concrete used in this study. While the RPC column with $1 \%$ volumetric ratio was stiffer than the $\mathrm{NC}$ column. $\mathrm{HC}$ columns used in this research have three different volumetric ratios of steel fibres, $(0.5,1$ and 1.5) and the thickness of the RPC layer was $40 \mathrm{~mm}$. Load-displacement curves for these columns showed that by adding steel fibres, the column will be stiffer than the NC column. For the specimen with $1.5 \%$ of steel fibres, the curves showed that it was stiffer than the RPC column cast in this study, therefore, from economic point of view, it is recommended to use $\mathrm{HC}$ columns with high percentage of steel fibres (1.5\%), because their cost will be less than the high cost of pure RPC columns.

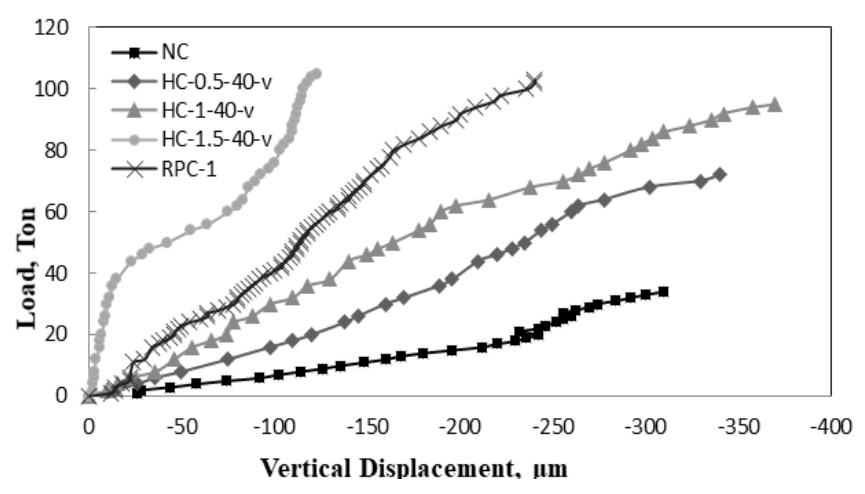

\section{Figure 6: Vertical Load-Displacement Curves for Research Specimens \\ (Different Volumetric Ratio of Steel Fibres)}

On the other hand, the Load-horizontal displacements were shown in Fig.7. The same conclusions were obvious. The load-displacement curve for the NC column is less stiff than the other types of concrete used. $\mathrm{HC}$ columns used in this research have three different volumetric ratios of steel fibres, $(0.5,1$ and 1.5$)$ and the thickness of the RPC layer was $40 \mathrm{~mm}$. Load-displacement curves showed that the first two percentages were closer to the NC behaviour while increasing the percentage to $1.5 \%$ made its behaviour approaching that of the RPC column.

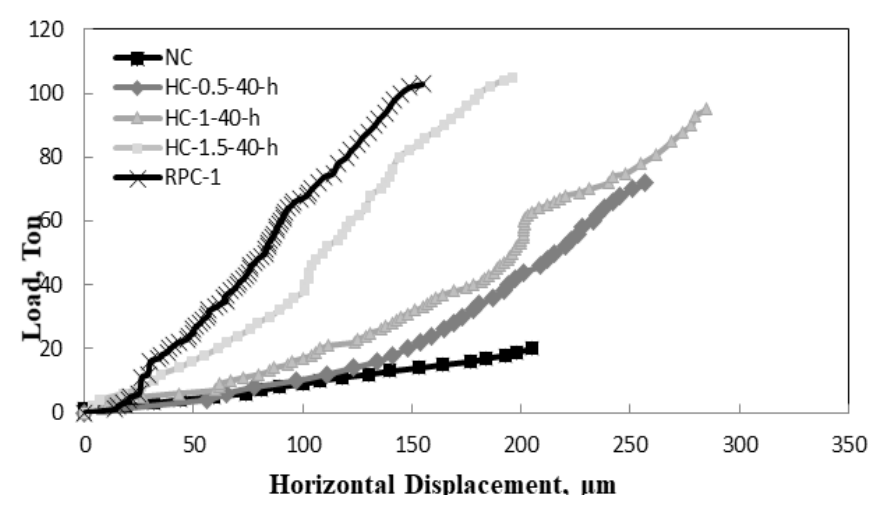

Figure 7: Horizontal Load-Displacement Curves for Research Specimens

(Different Volumetric Ratio of Steel Fibres)

\section{The second variable/RPC thickness}

The load-displacement curves for this variable are shown in Figs. 8 and 9. Fig. 8, representing the vertical displacements, shows that the NC column is less stiff than the RPC column cast with $1 \%$ volumetric ratio. Using a thickness of $20 \mathrm{~mm}$ of RPC in casting the hybrid column gave a behaviour similar to the NC column. While increasing the thickness of RPC to $40 \mathrm{~mm}$ gave a significant increase in the load-displacement curve that almost approached the RPC column. 


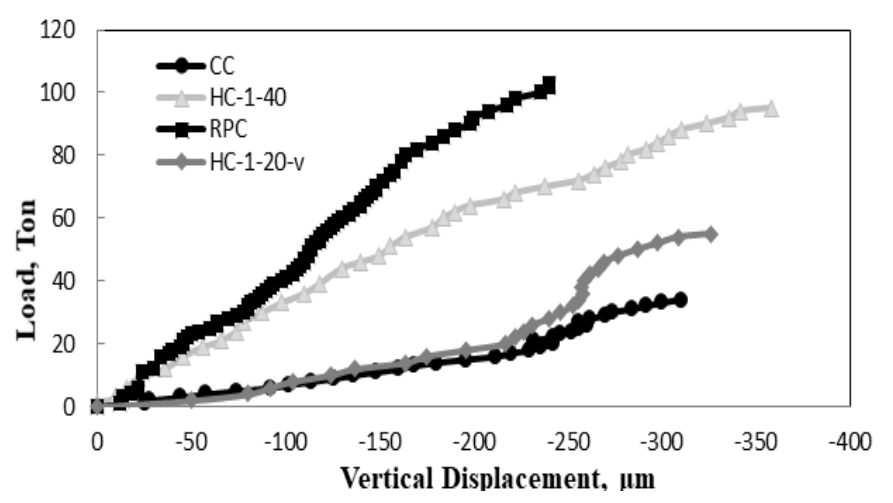

Figure 8: Vertical Load-Displacement Curves for Research Specimens

(Different RPC Thickness)

For the horizontal load-displacement curve, shown in Fig. 9, both hybrid columns were similar in behaviour at the beginning of the test (about $40 \%$ of the load), then with increasing load the $\mathrm{HC}-1-40$ became stiffer than the HC-1-20.

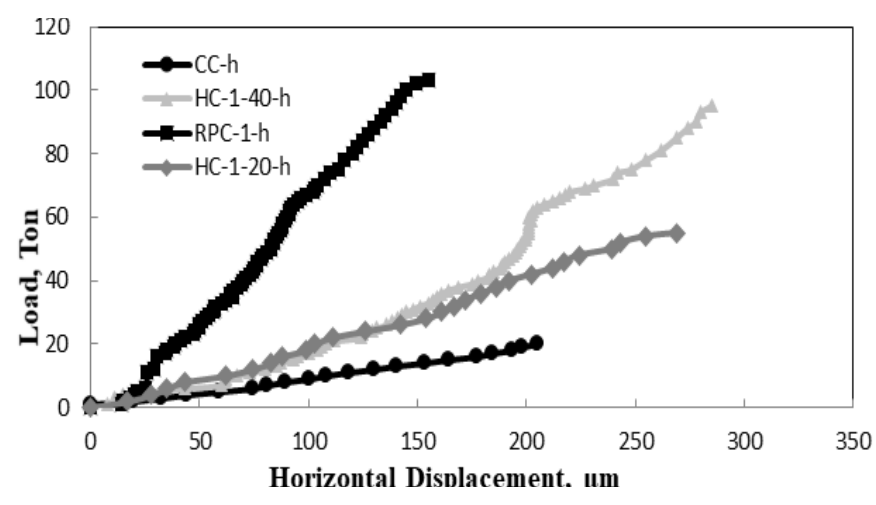

Figure 9: Horizontal Load-Displacement Curves for Research Specimens

(Different RPC Thickness)

\section{Effect of Variable Studied}

Two variables were studied throughout this research work, the percentage of the volumetric ration of steel fibres used and the RPC thickness.

\section{Effect of Steel Fibres}

The effect of using different volumetric ratios of steel fibres is shown in Figure 10. Increasing the ratio used, in the $\mathrm{HC}$ columns, from $0.5 \%$ to $1.5 \%$ helped in enhancing the load failure loads of these columns with respect to the NC column. The percentages of increase for the $\mathrm{HC}-0.5, \mathrm{HC}-1$ and $\mathrm{HC}-1.5$ were $112 \%, 179 \%$ and $209 \%$, respectively. The $1.5 \%$ volumetric ratio was highly effe tive which gave a percentage of increase $(209 \%)$ higher than the pure RPC column (203\%), therefore it is recommended to use this ratio in the hybrid combination for economic reasons.

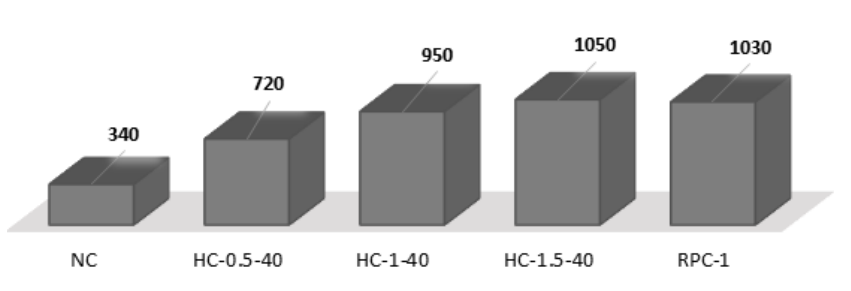

Figure 10: Effect of Steel Fibres on the Failure Loads

\section{Effect of RPC Thickness}

The effect of the RPC layer thickness used in the hybrid combination is shown in Figure 12. Four thicknesses were included in this study, 0 (pure NC), $20 \mathrm{~mm}, 40 \mathrm{~mm}$ and $50 \mathrm{~mm}$ (pure RPC). Increasing the thickness from 0 to 50 enhanced the load carrying capacity of the columns tested in this research. The percentages of increase (with respect to the NC column) for the HC-1-20, HC-140 and RPC-1 were $62 \%, 179 \%$ and $203 \%$, respectively. Using a small layer of RPC in the hybrid combination increased the failure load with respect to the NC column. This layer provided an extra confinement for the longitudinal reinforcement (in the NC portion of the hybrid column) in addition to the ties. Doubling the thickness of the RPC layer almost doubled the failure load. This increase in the failure load can be attributed to the inclusion of the longitudinal steel reinforcement (with the confining ties) within the RPC layer in addition to the presence of the steel fibres

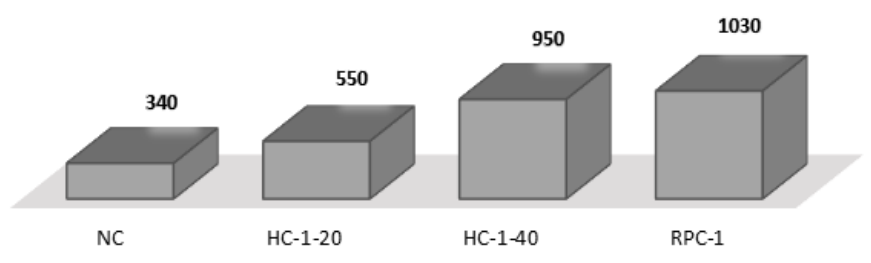

Figure 11: Effect of RPC Thickness on the Failure Loads

\section{CONCLUSIONS}

The use of the hybrid combination proved to be beneficial economically and practically, because of the good properties of the RPC layer regarding the high strength (both in compression and tension), high toughness, and durability. Therefore, the tested $\mathrm{HC}$ specimens bore higher loads and eventually lower cost than the pure RPC specimens. Using the small percentage of the volumetric ratio of steel fibres in the hybrid combination improved the behaviour of the columns with respect to the NC columns, but increasing these ratios gave an enhancement in the failure loads of the $\mathrm{HC}$ columns which made them approach the RPC columns, therefore, from economic point of view, it is recommended to use the hybrid combination with high percentage of steel fibres $(1.5 \%)$, because their cost will be less than the high cost of pure 
RPC columns and they produced almost the same capacity. Decreasing the RPC layer thickness from $40 \mathrm{~mm}$ to $20 \mathrm{~mm}$ gave $62 \%$ enhancement in the failure load with respect to the NC column; but this enhancement was about half the value of the hybrid columns with $40 \mathrm{~mm}$ thickness of RPC. Nevertheless, this enhancement was less in the horizontal load-displacement curves, which proves that this combination provided an enhancement in the compressive behaviour more than the tension behaviour. Doubling the thickness of the RPC layer almost doubled the failure load. This increase in the failure load can be attributed to the inclusion of the longitudinal steel reinforcement (with the confining ties) within the RPC layer in addition to the presence of the steel fibres

\section{ABBREVIATIONS}

HC Hybrid Concrete

HSC High Strength Concrete

NC Normal Concrete

LVDT Linear Variable Differential Transformer

RPC Reactive Powder Concrete

UHSC Ultra High Strength Concrete

\section{REFERENCES}

1. Yusof, M. A., Nor, N. M., Zain, M. F. M., Peng, Ng. Ch.,Ismail, A., Sohaimi, R. M. and Ahmad, A. M., (2011). Mechanical properties of hybrid steel fibr reinforced concrete with diff rent aspect ratio. Australian Journal of Basic and Applied Sciences, 5(7), pp. 159-166, ISSN 1991-8178.

2. Shah, S. (1997). High-performance concrete: controlled performance concrete. NSF center for science and technology of advanced cement-based materials, Magazine of Concrete Research, 49, No. 178, Mar., 1-3.

3. Bayasi, Z., (1989). Development and mechanical characterization of carbon fibre reinforced cement composites and mechanical properties and structural applications of steel fibre reinforced concrete, Ph.D. Thesis, Michigan State University, USA, pp: 1-199, Sited by [1].

4. Russell, H. G. and Graybeal, B. A (2013). UItra-high-performance concrete: A State-of-the-Art report for the bridge community. June. Publication No. FHWA-HRT-13-060.

5. Berry, M., Snidarich, R. and Wood, C (2017). Development of non-proprietary ultra-high-performance concrete. Final Report prepared for The State of Montana Department of Transportation, December, Publication No. FHWA/MT-17-010/8237-001.
6. Wu, X., Kang, T. H. K., Mpalla, I. B. and Kim, Ch. S. (2018). Axial load testing of hybrid concrete columns consisting of UHPFRC tube and normal-strength concrete core. International Journal of Concrete Structures and Materials, DOI 10.1186/s40069-0180275-2, ISSN 1976-0485 / elSSN 2234-1315, Published online 29, May.

7. Larsen, I. L., Thorstensen, R. T. (2020). The influenc of steel fibres on compressive and tensile strength of ultra high performance concrete. Construction and Building Materials, V. 256, 119459. https://doi. org/10.1016/j.conbuildmat.2020.119459

8. HABEL, K. (2004). Structural behaviour of elements combining ultra-high-performance fibre reinforced concretes (UHPFRC) and reinforced concrete. PhD thesis, Federal Institute of Technology in Lausanne, France.

9. Resheq, A. (2018). Behavior of hybrid concrete columns under axial compression loads. MATEC Web of Conferences 162, 04021, https://doi.org/10.1051/ mateNConf/201816204021, BCEE3-2017.

10. Mohammed, A.H., Hasan, Q.A., Sarsam, K.F. (2020). The influence of reinforcement on the torsion capacity of the hybrid beams. Journal of Engineering Science and Technology Vol. 15, No. 1 (2020) 426 436, Web of Science [v.5.32] - Web of Science Core Collection Full Record (webofknowledge.com)

11. Hamid, M. M., Yassin, L. A. and Mohammed, A. H. (2020). Behavior of hybrid reinforced concrete columns. IOP Conference Series: Materials Science and Engineering: Doi:10.1088/1757899X/737/1/012033.

12. Danha, L. S., Abdul-hussien, Z. A., Abduljabbar, M. S. and Yassin, L. A. (2020). Flexural behavior of hybrid ultra-high-performance concrete. IOP Conf. Series: Materials Science and Engineering 737 (2020) 012008, doi:10.1088/1757-899X/737/1/012008.

13. Kumar, S. A. H., Rizvi, S. H., Raza, M. S. and Ansari, J. K. (2020). Effects of steel fibres on fresh and hardened properties of concrete, Civil and Environmental Engineering Reports, Open access Published Online: 09 Nov. pp186-199 DOI: https://doi. org/10.2478/ceer-2020-0039

14. ASTM Designation: C39/C39M-14a (2014). Standard test method for compressive strength of cylindrical concrete specimens. ASTM International, 100 Barr Harbor Drive, PO Box C700, West Conshohocken, PA 19428-2959, United States.

15. ASTM Designation: C469/C469M-14 (2014). Standard test method for static modulus of elasticity and poisson's ratio of concrete in compression. ASTM International, 100 Barr Harbor Drive, PO Box C700, West Conshohocken, PA 19428-2959, United States. 
16. ASTM Designation: C496/C496M-11 (2011). Standard test method for splitting tensile strength of cylindrical concrete specimens. ASTM International, 100 Barr Harbor Drive, PO Box C700, West Conshohocken, PA 19428-2959, United States.
17. ASTM Designation: C78/C78M-10, 1(2010). Flexural strength of concrete (using simple beam with third-point loading). ASTM International, 100 Barr Harbor Drive, PO Box C700, West Conshohocken, PA 19428-2959, United States. 